\title{
Manipulating Metallogel Properties by Luminogens and Their Applications in Cell Imaging
}

\author{
Arnab Biswas, ${ }^{\dagger}$ Sujay Mukhopadhyay, ${ }^{\dagger}$ Roop Shikha Singh, ${ }^{\dagger}$ Ashish Kumar, ${ }^{\dagger}$ Nishant Kumar Rana, ${ }^{\ddagger}$ \\ Biplob Koch, ${ }^{\ddagger}$ and Daya Shankar Pandey*
}

${ }^{\dagger}$ Department of Chemistry, Institute of Science, and Department of Zoology, Institute of Science, Banaras Hindu University, Varanasi 221 005, Uttar Pradesh, India

\section{Supporting Information}

ABSTRACT: Manipulating gelation properties of the isomeric zincterpyridine complexes C-1 (nongelator) and C-2 (gelator) using three different luminescent dyes, viz., acridine yellow (AY), ethidium bromide (EB), and azido-boron dipyrromethene, have been described. Hybrid gels created by the combination of $\mathrm{C}-1, \mathrm{C}-2$, and above-mentioned dyes have been termed complex-luminogen mixed gels (CLMGs). Ensuing CLMGs have been thoroughly characterized by spectral, morphological, and rheological studies. Cytotoxicity measurements and imaging against breast cancer cell line MDA-MB-231 unveiled that three out of the five CLMGs can be effectively used for cell imaging. Interestingly, direct use of the metalcontaining hybrid gels for live cell imaging which is a distinctive approach, has been successfully achieved with significantly encouraging results.

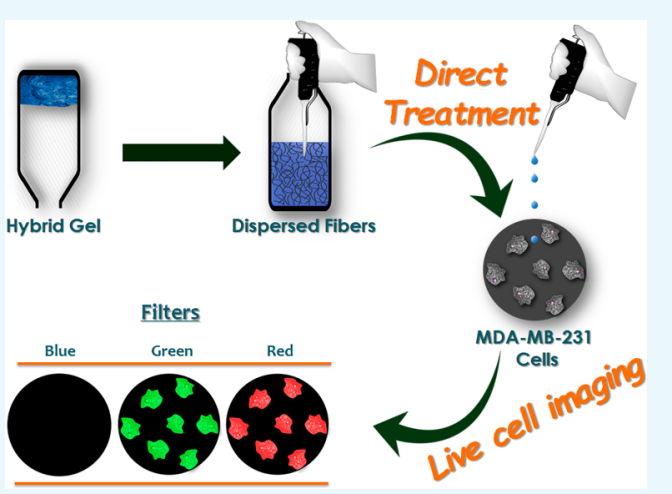

\section{INTRODUCTION}

Low molecular weight gels (LMWGs) have seen a large surge since past decade because of their potential applications in diverse areas, such as adhesive materials, molecular electronics, optoelectronics, sensing, tissue engineering, drug delivery, pharmaceuticals, cell culture, and so forth. ${ }^{1-12}$ There are several types of LMWGs, but metallogel is the one, which allows numerous solvents/ligands/metals to provide gels under various stimuli and is hence considered to be advantageous over other members of LMWGs. ${ }^{2,13-15}$ Currently, inorganicorganic hybrid gels have emerged as a magnificent successor of the metallogels in the LMWG category. Regulated by different physical interactions at the molecular level, they are often termed physical gels. ${ }^{16-18}$ It plays a vital role in retaining the native properties of the components ensuing versatility in their applications. Accordingly, terpyridyl complexes with extensive $\pi$-electronic conjugation and heteroatom-rich planar structures have shown great promise in metallo/multicomponent gelation. ${ }^{19-23}$ Further, the chelated terpyridyl moieties can generate frequent weak intermolecular interactions, and in addition, they have shown multifaceted applicability in biological fields. ${ }^{20,24-30}$

On the other hand, luminogens such as acridine yellow (AY) and ethidium bromide (EB) are widely used in biology. AY with its rich dye chemistry finds utility in solar cells, catalytic oxidation, biodegradation, spectrofluorometric analyses, and other investigative purposes, ${ }^{31-36}$ whereas EB serves as a classic staining agent for various biological systems. ${ }^{37-41}$ Despite its toxicity, mutagenicity, and carcinogenicity, EB is a known fluorescent tag used in molecular biology. Considering its selective exclusion by live cells, it is largely used for in vitro experiments as a staining agent to detect cell death. ${ }^{42,43}$ A closer look at their structure shows that they possess heteroatom-rich planar moieties and substantial $\pi$-electronic conjugation. On the basis of these features, they undergo different intermolecular interactions in multicomponent systems and hence hold the promise for multicomponent gelation. Interestingly, EB is ionic in nature, whereas AY is neutral. Another class of luminogens having the potential to assist gelation are the boron dipyrromethenes (BODIPYs), owing to their aggregation affinity. ${ }^{44-48}$ Notably, rich photochemistry and biocompatibility ${ }^{49-52}$ of BODIPYs have been extensively explored and have shown great promise in the fabrication of hybrid materials as well. ${ }^{52-60}$

Through an earlier communication, we reported that a zincterpyridyl complex Zn-TRPA-2 (C-2) produces a weak metallogel ZTP2G when triggered by an anion $\left(\mathrm{Cl}^{-}\right)$, wherein the isomeric complex Zn-TRPA-1 (C-1) could not form a proper gel under analogous conditions. ${ }^{61}$ Now in this work, following a similar gelation trajectory, we have tried to develop a series of multicomponent gels with potent biological applicability. To synthesize those multicomponent gels, the same isomeric pair of complexes, that is, C-1 and C-2, have been combined separately with three different luminogens of varying structural aspects, viz., acridine yellow (L-1), ethidium bromide (L-2), and azido-BODIPY (L-3) (Scheme 1). Every possible combination, that is, picking one complex and a luminogen at once, when triggered with the anion $\mathrm{Cl}^{-}$afforded

Received: November 22, 2017

Accepted: February 16, 2018

Published: May 21, 2018 
Scheme 1. Luminogens L-1-L-3 Used in the Complex-Luminogen Mixed Gelation

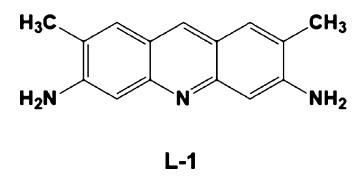

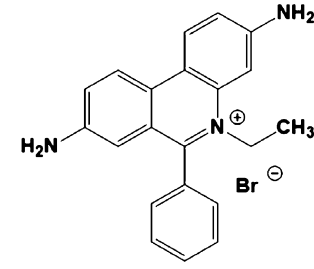

L-2

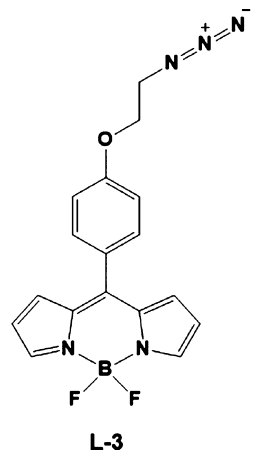

Scheme 2. Synthetic Routes Adopted for CLMGs Starting from the Complexes C-1 and C-2
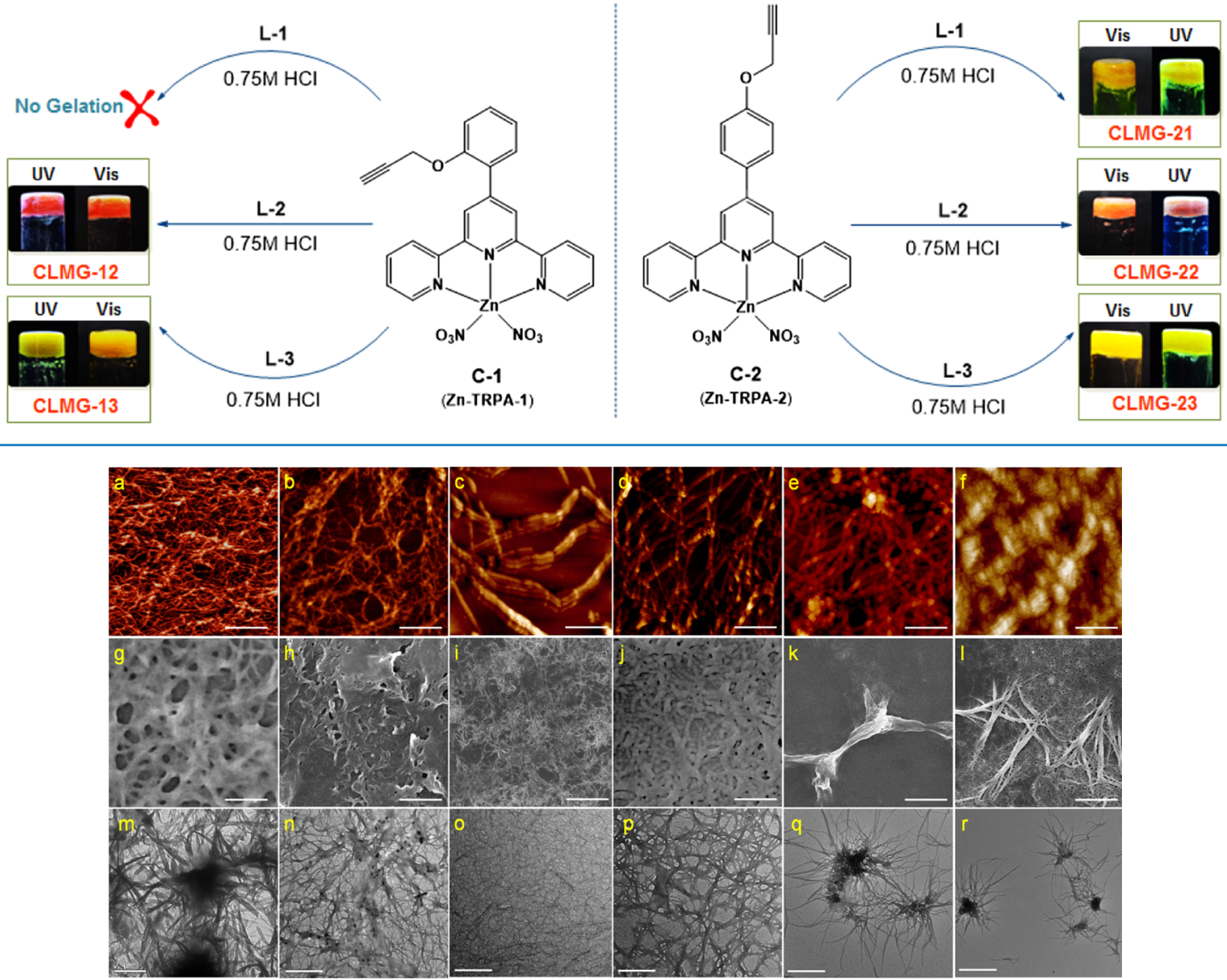

Figure 1. Morphological analyses: (a-f) AFM images (scale bar: $1 \mu \mathrm{m}),(\mathrm{g}-1)$ FESEM images (scale bar: $1 \mu \mathrm{m})$, and (m-r) TEM images (scale bar: $2 \mu \mathrm{m}$ for $\mathrm{m}$ and $100 \mathrm{~nm}$ for $\mathrm{n}-\mathrm{r}$ ) on the order: ZTP2G, CLMG-12, CLMG-13, CLMG-21, CLMG-22, and CLMG-23, clearly showing that CLMG fibers differ not only from each other with respect to their shape, arrangements, and dimensions but also from the ZTP2G (metallogel) fibers as well.

the series of gels, referred to as "complex-luminogen mixed gels" (CLMGs). After thorough morphological, photophysical, and rheological characterization of these CLMGs, we went on to investigate their possible applicability in live cell imaging which was evaluated in vitro against the breast cancer cell line MDA-MB-231. Another interesting fact associated with the present study is that we have used the CLMGs as dispersed fibers rather than the native form for entire set of biological experiments.

\section{RESULTS AND DISCUSSION}

Multicomponent gels, viz., CLMG-12 (C-1/L-2), CLMG-13 (C-1/L-3), CLMG-21 (C-2/L-1), CLMG-22 (C-2/L-2), and CLMG-23 (C-2/L-3), have been synthesized (Scheme 2) and thoroughly characterized by elemental analysis, infrared (IR) and ${ }^{1} \mathrm{H}$ NMR, atomic force microscopy (AFM), field emissive scanning electron microscopy (FESEM), transmission electron microscopy (TEM), UV-vis, and fluorescence spectroscopic and rheological studies.

IR and ${ }^{1} \mathrm{H}$ NMR Spectroscopy. For IR and ${ }^{1} \mathrm{H}$ NMR spectral studies, synthesized CLMGs have been air-dried. The 


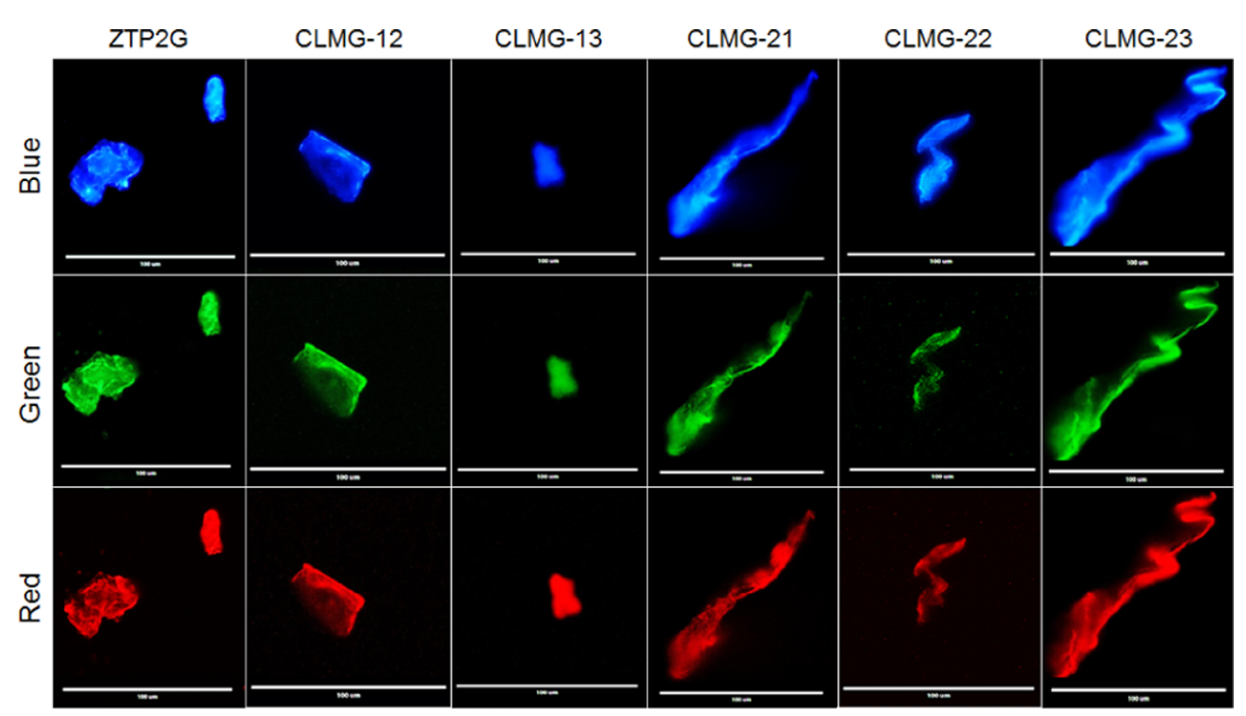

Figure 2. Fluorescence microscopy images for ZTP2G, CLMG-12, CLMG-13, CLMG-21, CLMG-22, and CLMG-23 showing aggregated nanofibers (obtained by diluting the gels with $\mathrm{MeOH}$ to $10^{-3} \mathrm{M}$ ) can emit under blue, green, or red filters (scale bars: $100 \mu \mathrm{m}$ ).

IR spectrum of $\mathrm{C}-1$ exhibited characteristic alkyne $(-\mathrm{C} \equiv \mathrm{C}-)$ stretching at $2113 \mathrm{~cm}^{-1}$, whereas for C-2, it vibrated at 2124 $\mathrm{cm}^{-1}$. Interestingly, alkyne stretching showed a marked shift (2121 $\mathrm{cm}^{-1}$, CLMG-12 and $2119 \mathrm{~cm}^{-1}$, CLMG-13) for CLMGs relative to (Figure S1) $\mathrm{Zn}$ (II) complexes. Similar results have been observed for CLMG-21 $\left(2127 \mathrm{~cm}^{-1}\right)$, CLMG-22 (2129 $\left.\mathrm{cm}^{-1}\right)$, and CLMG-23 $\left(2125 \mathrm{~cm}^{-1}\right)$ also involving C-2 (Figure S2). Flattening/weakening of the existing bands and emergence of new bands for these CLMGs relative to the complex further suggested weak intermolecular interactions between the components in these systems. ${ }^{1} \mathrm{H}$ NMR spectra of the CLMGs have been acquired in dimethyl sulfoxide (DMSO)- $d_{6}$ (due to poor solubility of the dried gels in methanol- $\left.d_{4}\right)$ and compared with respective complex components ( ${ }^{1} \mathrm{H}$ NMR of $\mathrm{C}-1 / \mathrm{C}-2$; also acquired in DMSO$\left.d_{6}\right)$. Here too, comparative studies revealed some interesting results. For example, aromatic protons of the terpyridyl moiety resonated at $\delta 9.22 \mathrm{ppm}$ in complex $\mathrm{C}-1$ which experienced a huge upfield shift in CLMG-12 $(\delta 8.83 ; \Delta \delta \approx 0.38 \mathrm{ppm})$ and CLMG-13 $(\delta 8.88 ; \Delta \delta \approx 0.34 \mathrm{ppm})$. Again, methylene protons $\left(-\mathrm{CH}_{2}-\right)$ of the alkyne chain of C-1 $(\delta 5.03 \mathrm{ppm})$ shifted upfield ( $\delta 4.90, \Delta \delta \approx 0.14$ ppm, CLMG-12 and $\delta 4.94, \Delta \delta \approx$ 0.09 ppm, CLMG-13) (Figure S3). Similarly, terpyridyl protons of C-2 $(\delta 9.33 \mathrm{ppm})$ resonated at $\delta 9.00 \mathrm{ppm}$ for CLMG-21 $(\Delta \delta \approx 0.34 \mathrm{ppm}), \delta 8.99 \mathrm{ppm}$ for CLMG-22 $(\Delta \delta \approx 0.35 \mathrm{ppm})$, and $\delta 8.92 \mathrm{ppm}$ for CLMG-23 $(\Delta \delta \approx 0.41 \mathrm{ppm})$. The methylene protons $\left(-\mathrm{CH}_{2}-\right)$ of the alkyne chain $(\delta 5.021$ ppm) upfield-shifted ( $\delta$ 4.94, $\Delta \delta \approx 0.08$ ppm, CLMG-21; $\delta$ 4.93, $\Delta \delta \approx 0.09 \mathrm{ppm}, \mathrm{CLMG}-22$; and $\delta 4.91, \Delta \delta \approx 0.11 \mathrm{ppm}$, CLMG-23) (Figure S4). A significant shift for the characteristic signals in the spectra of CLMGs relative to the respective complexes strongly advocated the occurrence of substantial weak intermolecular interactions in these multicomponent systems.

Morphology and Fluorescence Microscopy. AFM, SEM, and TEM analyses revealed a fibrous network in the CLMGs. AFM analyses on CLMGs and ZTP2G have been made by taking equal strength of their diluted solutions $(5 \times$ $10^{-5} \mathrm{M}$ ). Images unveiled a rootlike entangled network for CLMG-12 (Figure 1b), long fibers (Figure 1c) with an arrangement similar to SATA cables for CLMG-13, a spider web-like network (Figure 1d) for CLMG-21, thin tape-like fibers for CLMG-22 (Figure 1e), and normal optical cable-like arrangement for fibers in CLMG-21 (Figure 1f). Notably, fibers of ZTP2G (Figure 1a) showed a thin thread-like morphology. The distinctive difference in the construction of fibers of pure metallogel (ZTP2G) to hybrid matrices (CLMGs) could be easily understood from the AFM analyses. SEM analyses corroborated well with the observations made from AFM studies. SEM images revealed that ZTP2G acquired entangled threads (Figure 1g) similar to that observed in AFM. For CLMGs too, SEM images are concordant to that of AFM (Figure $1 \mathrm{~h}-1$ ). TEM analyses provided significant information about the average dimension of the fibers. It showed that CLMG-12 fibers have an average dimension of $\sim 10 \mathrm{~nm}$ and CLMG-13 fibers have an average dimension of $\sim 5 \mathrm{~nm}$ (Figure 1n,o). The average fiber dimensions for CLMG-21, CLMG-22, and CLMG-23 have been found to be $\sim 15, \sim 6$, and $\sim 8 \mathrm{~nm}$, respectively (Figure $1 \mathrm{p}-\mathrm{r}$ ). Contextually, the average dimension for ZTP2G fibers was reported to be $\sim 30 \mathrm{~nm} .{ }^{61}$ Further, fluorescence microscopy images suggested that the synthesized CLMG fibers along with ZTP2G are fluorescent in nature and emit brightly under blue, green, or red filters (Figure 2).

UV-Vis and Fluorescence Spectroscopic Analyses. To investigate the interactions associated with the multicomponent gelation, UV-vis studies have been performed. An attempt has been made to work out whether the components in each CLMG are reactive toward each other under exclusive conditions (i.e., in the absence of a third species such as anion $\mathrm{Cl}^{-}$). Addition of $\mathrm{L}-1$ to $\mathrm{C}-1$ (in $\mathrm{MeOH}$ ) led to a mere overlap of their individual spectrum without any significant shift in characteristic bands (Figure S5a). However, the addition of $\mathrm{HCl}(0.75 \mathrm{M})$ to the resulting solution $(\mathrm{C}-1 / \mathrm{L}-1)$ led to a blue shift accompanied by an isosbestic point for the intraligand charge-transfer transition (ICT) band ${ }^{61,62}(340 \mathrm{~nm})$ assignable to $\mathrm{C}-1$. It indicated the replacement of $\mathrm{NO}_{3}^{-}$from C-1 triggered by anion $\mathrm{Cl}^{-}$. Other combinations, viz., C-1/L-2, C-1/ L-3, C-2/L-1, C-2/L-2, and C-2/L-3 too, displayed similar patterns (Figure S5). For L-3 characteristic, $\pi-\pi^{*}$ transition associated with the BODIPY moiety has been observed at $\sim 500$ nm. ${ }^{63-65} \mathrm{UV}-\mathrm{vis}$ analyses suggested that complexes and 
luminogens are essentially nonreactive to each other; thus, only weak intermolecular interactions might occur.

Fluorescence spectroscopic studies have also been performed to realize the interactions. The inorganic component $\mathrm{C}-1\left(10^{-5}\right.$ $\mathrm{M} ; \mathrm{MeOH})$ emits at $475 \mathrm{~nm}\left(\lambda_{\text {ex }}, 340 \mathrm{~nm}\right)$ because of an $\mathrm{ICT}^{66}$ originating from the chelation of the terpyridyl core with $\mathrm{Zn}^{2+}$. Upon the addition of the luminogen L-1 (1.0 equiv) to a solution of C-1, the emission due to C-1 appeared at $500 \mathrm{~nm}$ with a red shift of $25 \mathrm{~nm}$ (Figure S6). This may be attributed to the enhanced ICT in C-1 under the influence of a luminogen. Further, the addition of $\mathrm{HCl}(0.75 \mathrm{M})$ quenched the emission of the resulting solution, demonstrating the molecular assembly, that is, nanofibers formation triggered by $\mathrm{Cl}^{-}$. Further, emission maxima retained its position $(500 \mathrm{~nm})$ which suggested an insignificant change in the enhanced ICT. Thus, even after aggregation, L-1 influences ICT in C-1. Similar observations have been made for L-1 after its treatment with C2 (Figure S6). A greater red shift of $50 \mathrm{~nm}(450 \rightarrow 500 \mathrm{~nm})$ has been observed for this system under analogous conditions, suggesting greater influence of L-1 on the ICT for C-2 relative to that on C-1. On the other hand, other combinations, viz., C1/L-2, C-1/L-3, C-2/L-2, and C-2/L-3, do not show any significant change. Rather, in each case, quenching occurred implying the anion-triggered self-assembly process.

Average Lifetime. Average lifetime $\left(\tau_{\mathrm{av}}\right)$ measurements have been performed on CLMGs which revealed that CLMG21 (5.88 ns) has highest lifetime followed by CLMG-12 (5.17 ns), CLMG-23 (4.75 ns), CLMG-22 (4.54 ns), and CLMG-13 (4.02 ns) (Figure 3). The average lifetime for ZTP2G has been



Figure 3. Fluorescence average lifetime plot for CLMGs and ZTP2G showing CLMG-21 with the highest average lifetime among the synthesized gels.

calculated to be 2.93 ns. ${ }^{61}$ Again, similar measurements have been made on luminogens L-1-L-3 exclusively, and thereafter, a comparative analysis has been performed to realize the interaction between the components in the hybrid systems (CLMGs). It has been found that $\tau_{\mathrm{av}}$ of L-1 (3.54 ns) is greater than those of L-2 (3.45 ns) and L-3 (2.76 ns) (Figure S7), but all of these are much lower with respect to CLMGs. The average lifetime signifies that species with higher $\tau_{\mathrm{av}}$ is likely to persist for longer period in the excited state. Therefore, experimental results advocated that luminogens do interact with complexes in CLMGs, and the extent of interaction is greater in CLMG-12 relative to that in CLMG-13 which further follows the order: CLMG-21 > CLMG-22 > CLMG-23. Nevertheless, substantial lifetimes of these CLMGs supported their potential usage in fluorescence imaging.
Rheological Analyses. Mechanical strength of the fibrous self-assemblies has been worked out by performing rheological experiments under analogous conditions. Viscoelastic behavior has been investigated by rheological studies at room temperature using freshly prepared CLMGs. Storage (or viscous, $G^{\prime}$ ) and loss (or elastic, $G^{\prime \prime}$ ) moduli of the CLMGs have been measured as a function of dynamic oscillatory strain $(\gamma)$ and shear stress $(\tau)$ over a long range. Individual experiments with each of the CLMGs have been performed to investigate whether the synthesized materials satisfy the two essential criteria of a true gel phase, that is, $G^{\prime}>G^{\prime \prime}$ and $\Delta\left(G^{\prime} \approx G^{\prime \prime}\right) \geq 1$ order, which evidently illustrated their gel character.

Experimental results showed the $G^{\prime} / G^{\prime \prime}$ values for CLMG12 - 2800 Pa/250 Pa; CLMG-13-2550 Pa/260 Pa; CLMG21-420 Pa/40 Pa; CLMG-22-4800 Pa/380 Pa; and CLMG$23-12100 \mathrm{~Pa} / 1150 \mathrm{~Pa}$ (Figures S8-12). Comparative changes in the viscoelastic properties (storage/loss moduli) of the CLMGs from ZTP2G to CLMGs stimulated by the luminogens are shown in Figure 4. $G^{\prime} / G^{\prime \prime}$ values clearly
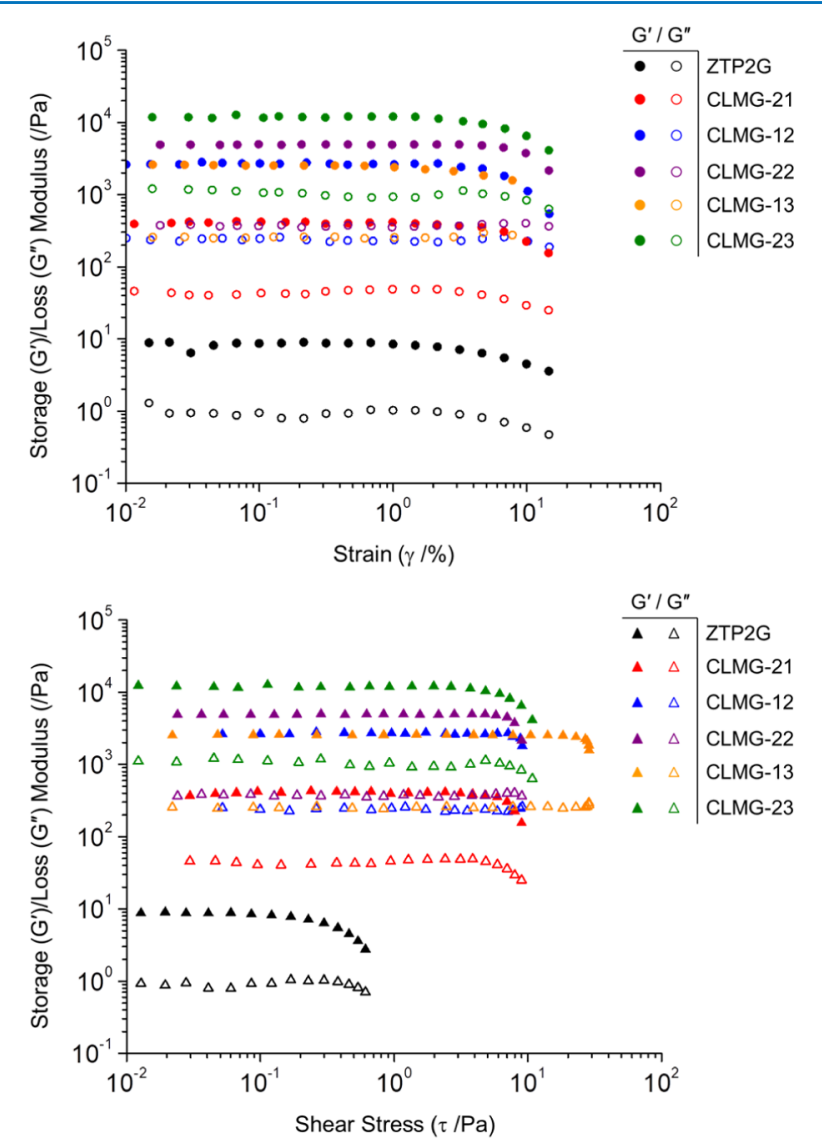

Figure 4. Comparative rheological plots showing (a) oscillation strain $(\gamma)$ sweep and (b) shear stress $(\tau)$ sweep of elastic or storage $\left(G^{\prime}\right)$ and loss $\left(G^{\prime \prime}\right)$ moduli of the synthesized gels. CLMG-23 has the highest storage/loss moduli, whereas CLMG-21 has the least among the hybrid gels.

indicated CLMG-22 with the strongest viscoelastic character in this series. Such observed changes in rheological properties may be attributed to the structural disparity of the luminogens. For example, acridine yellow (L-1) has a nonionic structure, whereas both ethidium bromide (L-2) and azido-BODIPY (L-3) are ionic. Therefore, L-2 and L-3 are likely to involve in weak electronic interactions unlike L-1. These weak electronic 
interactions aid in the strengthening of the molecular gel network. Our experimental results have also suggested for the same where it has been observed that $G^{\prime} / G^{\prime \prime}$ for CLMG-21 is much lower than those for CLMG-22 or CLMG-23. On the other hand, metallogel ZTP2G displayed weak viscoelastic characteristics with a $G^{\prime}$ of $10 \mathrm{~Pa}$ and a $G^{\prime \prime}$ of $1 \mathrm{~Pa}^{61}$ Experimental evidences suggested that all luminogen hybridized CLMGs are quite strong relative to the ones belonging to the metallogel ZTP2G.

MTT Assay and Cytotoxicity. To have an understanding about the applicability of the gel nanofibers in biological systems, assessment of their toxicity is crucial. In this regard, to realize the cytotoxicity of the synthesized CLMGs and metallogel ZTP2G nanofibers, 3-(4,5-dimethylthiazol-2-yl)2,5-diphenyltetrazolium bromide (MTT) assays have been performed against breast cancer cell line MDA-MB-231. Cells were treated with a range of concentrations $(5-100 \mu \mathrm{M})$ for each gel species. MTT assay revealed that it is not possible to evaluate $\mathrm{IC}_{50}$ for ZTP2G nanofibers up to $100 \mu \mathrm{M}$, indicating its nontoxic nature toward the cell line (Figure 5). Similar

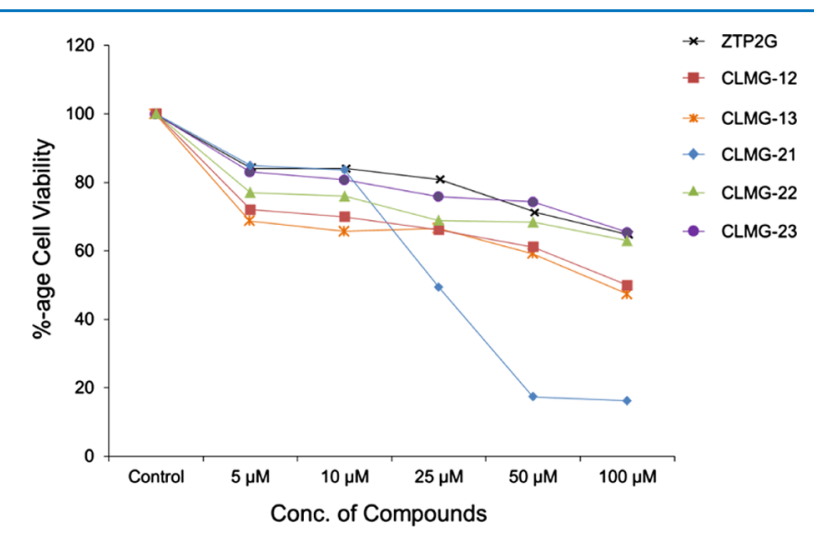

Figure 5. MTT assay performed in the concentration range (5-100 $\mu \mathrm{M})$ for each gel, revealed that CLMG-22 and CLMG-23 displayed $\mathrm{IC}_{50}>100 \mu \mathrm{M}$, whereas CLMG-12 and CLMG-13 showed $\mathrm{IC}_{50}<100$ $\mu \mathrm{M}$. The lowest $\mathrm{IC}_{50}$ value has been observed for CLMG-21 which is $\sim 25 \mu \mathrm{M}$. Again, metallogel ZTP2G displayed an $\mathrm{IC}_{50}$ of $>100 \mu \mathrm{M}$. It is clear from the data that only CLMG-21 shows significant cytotoxicity.

protocol was followed for other CLMGs, and the results suggested that CLMG-12 and CLMG-13 ( IC $_{50}$ between 50 and $100 \mu \mathrm{M}$ for each) showed negligible toxicity, whereas CLMG$21\left(\mathrm{IC}_{50} \approx 25 \mu \mathrm{M}\right)$ displayed toxicity toward cytoplasm of MDA-MB-231 cells. CLMG-22 and CLMG-23 ( IC $_{50}<100 \mu \mathrm{M}$ for each) were found to be nontoxic to the cells as their $\mathrm{IC}_{50}$ values could not be achieved up to the highest tested concentration (Figure 5). On the basis of the respective $\mathrm{IC}_{50}$ values, we conclude that only CLMG-21 shows significant toxicity, whereas other CLMGs and metallogel ZTP2G should be considered nontoxic to MDA-MB-231 cells.

Live Cell Imaging. Because the synthesized gels emitted strongly under the three primary emission filters, viz., red, green, and blue, their efficacy as a biological staining agent has been evaluated in vitro against breast cancer cell line MDA-MB231. The cells were incubated for $24 \mathrm{~h}$ with different concentrations $(5-100 \mu \mathrm{M})$ of ZTP2G and monitored by a fluorescent microscope. It was observed that fibers are unable to stain the cells even at their highest concentration $(100 \mu \mathrm{M})$ (Figure 6); however, the dispersed CLMG fibers offered interesting results when subjected to similar protocols. Cells



Figure 6. Live cell imaging with MDA-MB-231 cells treated with dispersed fibers of ZTP2G and CLMGs (scale bar: $100 \mu \mathrm{m}$ ). Upon treatment with ZTP2G $(100 \mu \mathrm{M})$ and CLMG-12 $(50 \mu \mathrm{M})$, the cells could not emit properly. When treated with CLMG-13 $(50 \mu \mathrm{M})$ and CLMG-23 (50 $\mu \mathrm{M})$, MDA-MB-231 cells emitted brightly under green and red filters, whereas on treatment with CLMG-21 $(25 \mu \mathrm{M})$ and CLMG-22 $(50 \mu \mathrm{M})$, the cells emitted selectively under green and red filters, respectively.

treated with CLMG-13 and CLMG-23 (50 $\mu \mathrm{M}$ each) fluoresced brightly under green and red filters. CLMG-22 (50 $\mu \mathrm{M})$ treated cells emitted brightly under the red filter, whereas CLMG-21 $(25 \mu \mathrm{M})$ treated ones emitted selectively under the green filter. However, CLMG-12 fibers were unable to stain the cells even at the highest permissible $(50 \mu \mathrm{M})$ concentration. Another interesting observation was that CLMG nanofibers stain only the cytoplasm but not the nucleus. Taken together, fluorescence imaging experiments in live cells suggested that these hybrid CLMGs may be used explicitly for cytosolic staining, whereby they offer desirable contrast during combinatorial fluorescence imaging with other fluorophores.

Another interesting inference which ensues is that metallogel nanofibers become potential cytosolic staining agents in combination with luminogens. Combining our observations from the cytotoxicity analyses with their staining potential, it can be concluded that CLMG-13, CLMG-22, and CLMG-23 are sufficiently nontoxic and efficient cytosolic markers for live cell imaging. To understand the role of precursor complexes toward the applicability shown by the hybrid gel materials in live cell imaging, similar experiments have been performed with C-1 and C-2 as well (Figures S13 and 14). MTT assay for C-1 and $\mathrm{C}-2$ suggested that they are nontoxic as their $\mathrm{IC}_{50}$ values could not be achieved up to the highest tested concentration $(100 \mu \mathrm{M})$. MDA-MB-231 cells upon treatment with C-1 and $\mathrm{C}-2$ emitted effectively under blue and green filters by virtue of their fluorescent nature. Once C-2 forms gel fibers (ZTP2G) via the self-assembly process, its emission quenches. ZTP2G fibers are unable to make the cells emissive under any of the blue/green/red filter. Our approach clearly shows that it is the incorporation of luminogen in the hybrid gel system that makes 
them suitable for fluorescence imaging of live cells. In particular, this work illustrates an unparalleled trait of hybrid gels riding on their excellent emission properties, that is, their direct administration to the cells to furnish and serve as desired fluorescence alternatives during live cell imaging.

\section{CONCLUSIONS}

This work deals with detailed synthesis of five anion-triggered hybrid gels, their thorough characterization, and unconventional in vitro applications. Syntheses of these hybrid gels have been carried out by remodeling of complex nanofibers with simple luminogens. After meticulous investigation on their diverse gel characteristics, interactions between the components, and photophysical behavior, an off-center approach has been realized, that is, comprehensive cytotoxicity assay and live cell imaging performed using the synthesized materials. It has been established that luminogen-derived gels CLMG-13, CLMG-22, and CLMG-23 serve as efficient fluorescent staining agents for cell cytoplasm and are suited for in vitro applications. This approach finds itself unique in its kind because such explicit usage of a gel fiber that performs the role of a fluorophore in live cell imaging has not been illustrated earlier. This report also outlines an alternative strategy for transportation of small molecules into the cell cytoplasm transported by hybrid nanofibers. Again, ethidium bromide, a classical biomarker for dead cells, finds an unorthodox usage in the live cell imaging which marks this report as the pioneer in its class. From another perspective, this report offers significant clue for the transportation of ionic species through the cell membrane considering the ionic nature of ethidium bromide.

\section{EXPERIMENTAL SECTION}

Materials and Methods. 2,7-Dimethylacridine-3,6-diamine (acridine yellow, AY, L-1), 3,8-diamino-5-ethyl-6-phenylphenanthridin-5-ium bromide (ethidium bromide, EB, L-2), pyrrole, trifluoroacetic acid, 2-/4-hydroxybenzaldehyde, 1,2dibromoethane, sodium azide $\left(\mathrm{NaN}_{3}\right)$, triethylamine, borontrifluoride diethyletherate $\left(\mathrm{BF}_{3} \cdot \mathrm{Et}_{2} \mathrm{O}\right)$, 2,3-dichloro-5,6-dicyano1,4-benzoquinone, potassium carbonate $\left(\mathrm{K}_{2} \mathrm{CO}_{3}\right)$, propargyl bromide, 2-acetylpyridine, sodium hydroxide $(\mathrm{NaOH})$, and ammonia $\left(\mathrm{NH}_{3}\right.$, liq. $)$ were purchased from Sigma-Aldrich Chemical Co., USA and used as received. Solvents were purchased from Merck, and S D Fine-Chem Ltd., Mumbai, India. The solvents were dried and distilled, following the standard procedures prior to their use. ${ }^{67}$ Trypsin-ethylenediaminetetraacetic acid solution and MTT were purchased from HiMedia, India, whereas DMSO from GeNie, Merck, India. Dulbecco's modified Eagle's medium (DMEM), fetal bovine serum, and antibiotic solution (10000 units $/ \mathrm{mL}$ penicillin and $10.0 \mathrm{mg} / \mathrm{mL}$ streptomycin) were purchased from Cellclone, Genetix Biotech Asia Pvt. Ltd. MDA-MB-231 a breast cancer cell line was procured from National Centre for Cell Science (NCCS), Pune.

Elemental Analyses. Elemental analyses for C, H, and $\mathrm{N}$ have been obtained on Elementar Vario EL III Carlo Erba 1108 from the microanalytical laboratory of the SAIF, Central Drug Research Institute Lucknow. CLMGs were vacuum-dried for sample preparation.

IR and ${ }^{1} \mathrm{H}$ NMR Spectroscopy. IR spectra were acquired on a PerkinElmer 577 spectrophotometer in $\mathrm{KBr}$ pellets. ${ }^{1} \mathrm{H}$ NMR spectra were obtained on JEOL AL 300 FT-NMR and JEOL AL 500 FT-NMR spectrophotometers at room temper- ature using tetramethylsilane $\left[\mathrm{Si}\left(\mathrm{CH}_{3}\right)_{4}\right]$ as an internal reference.

AFM/FESEM/TEM Analyses. The microscopy analyses were performed using CLMGs, diluted up to $5.0 \times 10^{-5} \mathrm{M}$ in methanol. AFM images were captured using a NTMDT Solver NEXT Russia. Samples were prepared by casting diluted gel on thin glass sheets, dried, and mounted. FESEM analyses were carried out using a Carl ZEISS microscope from Sigma $\mathrm{HD}$ in the In Lens mode at ETH: $5.00 \mathrm{kV}$. Diluted CLMG samples were casted on silicon wafers $(5.0 \mathrm{~mm} \times 5.0 \mathrm{~mm}$ square grids), dried, and gold-coated prior to mounting. TEM analyses have been performed on a JEOL JEM $2100 \mathrm{HR}$ Microscope. Operating voltage was maintained at $200 \mathrm{kV}$ on each occasion. Samples were prepared by casting diluted CLMGs on $\mathrm{Cu}$ grids.

UV-Vis and Fluorescence Spectroscopy. Electronic absorption (UV-vis) and emission (fluorescence) spectra were obtained on Shimadzu UV-1601 and PerkinElmer LS 55 spectrophotometers, respectively. Complexes C-1 and C-2 were dissolved in methanol maintaining a concentration of $10^{-5} \mathrm{M}$ to record all the spectra. Luminogens L-1, L-2, and L-3 were dissolved in methanol as well to obtain a $10^{-3} \mathrm{M}$ solution for each.

Fluorescence Average Lifetime Measurements. The lifetime measurements were made using a time-correlated single photon counting system from Horiba Yovin (Fluorocube-01-NL). The samples were excited at $343 \mathrm{~nm}$ using a picosecond diode laser (Pico Brite-375L). The data analysis was performed using IBH DAS (version 6, HORIBA Scientific, Edison, NJ) decay analysis software. Here also, $5.0 \times 10^{-5} \mathrm{M}$ diluted CLMGs were used to acquire the data.

Rheological Analyses. Measurements were made using a stress-controlled rheometer (Anton Paar Quality Control Rheometer Rheolab QC) equipped with stainless steel parallel plates (20 $\mathrm{mm}$ diameter, $0.2 \mathrm{~mm}$ gap). Experiments were carried out on freshly prepared gels. Linear viscoelastic regions for the samples were determined by measuring the storage modulus $G^{\prime}$ (associated with energy storage) and loss modulus $G^{\prime \prime}$ (associated with the loss of energy) as a function of stress amplitude. Dynamic oscillatory work was maintained at a frequency of $1 \mathrm{rad} \mathrm{s}^{-1}$. Following tests were performed: by increasing the amplitude of oscillation up to $100 \%$ apparent strain on shear, time. All measurements were conducted in triplicate.

Syntheses. Complexes C-1, C-2, and metallogel ZTP2G have been synthesized following our earlier procedure. ${ }^{61}$ AzidoBODIPY (L-3) has been synthesized by the reported procedure. $^{68}$ Syntheses of the CLMGs are described below.

CLMG-12. C-1 (20 $\mu \mathrm{M}, 11.0 \mathrm{mg} / \mathrm{mL})$ and L-2 $(20 \mu \mathrm{M}, 7.90$ $\mathrm{mg}$ ) were added to a vial containing methanol $(1.0 \mathrm{~mL})$, and the contents of the vial were stirred well for $5 \mathrm{~min}$ to make it homogeneous. Subsequently, $0.75 \mathrm{M} \mathrm{HCl}$ was added slowly to it (dropwise) with minimum disturbance. The addition of each drop led to fibrous aggregates observable by the naked eye. After the addition of $250 \mu \mathrm{L}$ acid, the vial was inverted to check the stability of the gel (1.79 wt \%). CHN analysis for $\mathrm{C}_{39} \mathrm{H}_{32} \mathrm{BrCl}_{2} \mathrm{~N}_{6} \mathrm{OZn}$. Found: C, 60.08; $\mathrm{H}, 4.65 ; \mathrm{N}, 8.94$; Calcd: C, 60.46; H, 4.17; N, 9.40.

CLMG-13. In a glass vial, $1.0 \mathrm{~mL}$ of $20 \mu \mathrm{M}$ methanolic C-1 $(11.0 \mathrm{mg} / \mathrm{mL})$ and $20 \mu \mathrm{M} \mathrm{L}-3(7.10 \mathrm{mg})$ were mixed and stirred well for $5 \mathrm{~min}$ to make it homogeneous. $\mathrm{HCl}(0.75 \mathrm{M})$ was added dropwise to it. The appearance of fibrous aggregates with each drop was visible by the naked eye. After the addition 
of $300 \mu \mathrm{L}$ of acid, the vial was inverted to check the stability of the gel (1.8 wt \%). CHN analysis for $\mathrm{C}_{41} \mathrm{H}_{31} \mathrm{BCl}_{2} \mathrm{~F}_{2} \mathrm{~N}_{8} \mathrm{O}_{2} \mathrm{Zn}$. Found: C, 57.68; H, 3.65; N, 12.94; Calcd: C, 57.74; H, 3.66; $\mathrm{N}, 13.14$.

CLMG-21. An almost similar procedure has been followed for the synthesis of CLMG-21. In this case, $20 \mu \mathrm{M} \mathrm{L}-1(4.7 \mathrm{mg})$ was added to $1.0 \mathrm{~mL}$ of $20 \mu \mathrm{M}$ methanolic C-2 (11.0 mg), followed by $300 \mu \mathrm{L}$ of $0.75 \mathrm{M} \mathrm{HCl}$. The vial was kept undisturbed for 5-10 min and inverted to confirm gelation (1.47 wt \%). CHN analysis for $\mathrm{C}_{39} \mathrm{H}_{32} \mathrm{Cl}_{2} \mathrm{~N}_{6} \mathrm{OZn}$. Found: $\mathrm{C}$, 63.18; H, 4.65; N, 10.94; Calcd: C, 63.56; H, 4.38; N, 11.40.

CLMG-22. Here, $20 \mu \mathrm{M} \mathrm{L}-2(7.90 \mathrm{mg})$ was mixed thoroughly with $1.0 \mathrm{~mL}$ of $20 \mu \mathrm{M} \mathrm{C}-2(11.0 \mathrm{mg})$ prior to the dropwise addition of $250 \mu \mathrm{L}$ of $0.75 \mathrm{M} \mathrm{HCl}$. Next, the vial was inverted to affirm gelation (1.79 wt \%). Elemental analysis for $\mathrm{C}_{39} \mathrm{H}_{32} \mathrm{BrCl}_{2} \mathrm{~N}_{6} \mathrm{OZn}$. Found: C, 59.90; H, 4.58; N, 9.12; Calcd: C, 60.46; H, 4.17; N, 9.40.

CLMG-23. Almost similar procedure has been followed for the synthesis of CLMG-23. L-3 $(20 \mu \mathrm{M}, 7.10 \mathrm{mg})$ has been added to $1.0 \mathrm{~mL}$ of $20 \mu \mathrm{M}$ methanolic C-2 (11.0 mg), followed by $250 \mu \mathrm{L}$ of $0.75 \mathrm{M} \mathrm{HCl}$. It was kept undisturbed for $1 \mathrm{~min}$ and then inverted to confirm gelation (1.8 wt \%). CHN analysis for $\mathrm{C}_{41} \mathrm{H}_{31} \mathrm{BCl}_{2} \mathrm{~F}_{2} \mathrm{~N}_{8} \mathrm{O}_{2} \mathrm{Zn}$. Found: $\mathrm{C}, 57.62 ; \mathrm{H}, 3.61 ; \mathrm{N}, 13.04$; Calcd: C, 57.74; H, 3.66; N, 13.14.

MTT Assay and Cytotoxicity. MDA-MB-231 cells with a density of 10000 per well were seeded and subsequently treated with different concentrations of ZTP2G, CLMG-12, CLMG-13, CLMG-21, CLMG-22, and CLMG-23 in a 96-well tissue culture plate and incubated in a $\mathrm{CO}_{2}$ incubator for $24 \mathrm{~h}$. After incubation, MTT $(5.0 \mathrm{mg} / \mathrm{mL})$ was added into each well and left for additional $2 \mathrm{~h}$ at $37{ }^{\circ} \mathrm{C}$. Formazan crystals were dissolved in $100 \mu \mathrm{L}$ of DMSO, and absorbance was measured spectrophotometrically on the ELISA plate reader with an excitation wavelength of $570 \mathrm{~nm}$. All the experiments were carried out in triplicate, and $\mathrm{IC}_{50}$ values of each sample were estimated.

Live Cell Imaging Experiments. To check the fluorescence effect of ZTP2G and CLMGs on cells, live cell imaging experiments were performed after $24 \mathrm{~h}$ treatment of MDA-MB-231 cells with CLMG-12, CLMG-13, CLMG-21, CLMG-22, and CLMG-23. Images were captured in an EVOS fluorescent microscope by Invitrogen.

Preparation of Samples. Compounds C-1/C-2 were dissolved in methanol to obtain $1.0 \times 10^{-2} \mathrm{M}$ solutions, and gels $\left(2.0 \times 10^{-2} \mathrm{M}\right.$; real concentration of CLMGs and ZTP2G) were diluted using methanol to obtain $1.0 \times 10^{-2} \mathrm{M}$ solutions containing dispersed gel fibers. The solution of compounds and gels were further diluted in the DMEM to reach the concentration $1.0 \times 10^{-4} \mathrm{M}$ (or $\left.100 \mu \mathrm{M}\right)$. Final concentration of the gels (i.e., $100.0 \mu \mathrm{M}$ ) has been used directly to the cell line. Different concentrations of the gels (from 5 to $100 \mu \mathrm{M}$ ) were treated to the cells under investigation, and final concentration of methanol in the cell culture medium was less than $0.1 \mathrm{v} / \mathrm{v} \%$.

\section{ASSOCIATED CONTENT}

\section{S Supporting Information}

The Supporting Information is available free of charge on the ACS Publications website at DOI: 10.1021/acsomega.7b01837.

${ }^{1} \mathrm{H}$ NMR, IR, UV-vis, and fluorescence spectra; average lifetime of luminogens (L-1-L-3); and individual rheology plots for CLMGs (PDF)

\section{AUTHOR INFORMATION}

Corresponding Author

*E-mail: dspbhu@bhu.ac.in.

ORCID

Daya Shankar Pandey: 0000-0002-6576-4234

\section{Author Contributions}

The manuscript was written through contributions of all authors.

Notes

The authors declare no competing financial interest.

\section{ACKNOWLEDGMENTS}

We are thankful to DST, New Delhi, India for the financial support through the scheme SR/S1/IC-25/2011. We are also thankful to Sagar Biswas and Sonam Mandani (Research Fellow, IIT Indore, India) for their valuable suggestions on rheological experiments. A.B. thanks CSIR, New Delhi, India for providing research fellowship [Chem.09/013(0335)/2010EMR-I].

\section{ABBREVIATIONS}

C-1, Zn-terpyridyl complex 1; C-2, Zn-terpyridyl complex 2; L1 , Luminogen 1 (or acridine yellow); L-2, Luminogen 2 (or ethidium bromide); L-3, Luminogen 3 (or azido-BODIPY); CLMG, Complex-Luminogen Mixed Gel; ZTP2G, Metallogel

\section{REFERENCES}

(1) Yang, Z.; Liang, G.; Xu, B. Enzymatic hydrogelation of small molecules. Acc. Chem. Res. 2008, 41, 315-326.

(2) Tam, A. Y.-Y.; Yam, V. W.-W. Recent advances in metallogels. Chem. Soc. Rev. 2013, 42, 1540-1567.

(3) Tu, T.; Fang, W.; Bao, X.; Li, X.; Dötz, K. H. Visual chiral recognition through enantioselective metallogel collapsing: synthesis, characterization, and application of platinum-steroid low-molecularmass gelators. Angew. Chem., Int. Ed. 2011, 50, 6601-6605.

(4) Sangeetha, N. M.; Maitra, U. Supramolecular gels: functions and uses. Chem. Soc. Rev. 2005, 34, 821-836.

(5) Ciriminna, R.; Fidalgo, A.; Pandarus, V.; Béland, F.; Ilharco, L. M.; Pagliaro, M. The Sol-Gel Route to Advanced Silica-Based Materials and Recent Applications. Chem. Rev. 2013, 113, 6592-6620.

(6) Patil, S. P.; Kim, S.-H.; Jadhav, J. R.; Lee, J.-h.; Jeon, E. M.; Kim, K.-T.; Kim, B. H. Cancer-Specific Gene Silencing through Therapeutic siRNA Delivery with B Vitamin-based nanoassembled Low-MolecularWeight Hydrogelators. Bioconjugate Chem. 2014, 25, 1517-1525.

(7) Lee, K. Y.; Mooney, D. J. Hydrogels for Tissue Engineering. Chem. Rev. 2001, 101, 1869-1880.

(8) Praveen, V. K.; Ranjith, C.; Armaroli, N. White-Light-Emitting Supramolecular Gels. Angew. Chem., Int. Ed. 2014, 53, 365-368.

(9) Kartha, K. K.; Babu, S. S.; Srinivasan, S.; Ajayaghosh, A. Attogram sensing of trinitrotoluene with a self-assembled molecular gelator. J. Am. Chem. Soc. 2012, 134, 4834-4841.

(10) Yan, X.; Cook, T. R.; Pollock, J. B.; Wei, P.; Zhang, Y.; Yu, Y.; Huang, F.; Stang, P. J. Responsive supramolecular polymer metallogel constructed by orthogonal coordination-driven self-assembly and host/guest interactions. J. Am. Chem. Soc. 2014, 136, 4460-4463.

(11) Po, C.; Tam, A. Y.-Y.; Wong, K. M.-C.; Yam, V. W.-W. Supramolecular self-assembly of amphiphilic anionic platinum(II) complexes: a correlation between spectroscopic and morphological properties. J. Am. Chem. Soc. 2011, 133, 12136-12143.

(12) Hirst, A. R.; Escuder, B.; Miravet, J. F.; Smith, D. K. High-tech applications of self-assembling supramolecular nanostructured gelphase materials: from regenerative medicine to electronic devices. Angew. Chem., Int. Ed. 2008, 47, 8002-8018.

(13) Chang, K.-C.; Lin, J.-L.; Shen, Y.-T.; Hung, C.-Y.; Chen, C.-Y.; Sun, S.-S. Synthesis and photophysical properties of self-assembled 
metallogels of platinum(II) acetylide complexes with elaborate longchain pyridine-2,6-dicarboxamides. Chem.-Eur. J. 2012, 18, 13121321.

(14) Dubey, M.; Kumar, A.; Gupta, R. K.; Pandey, D. S. $\mathrm{Li}^{+}$-induced selective gelation of discrete homochiral structural isomers derived from L-tartaric acid. Chem. Commun. 2014, 50, 8144-8147.

(15) Dubey, M.; Kumar, A.; Pandey, D. S. Homochiral coordination polymeric gel: $\mathrm{Zn}^{2+}$-induced conformational changes leading to $\mathrm{J}$ aggregated helical fibres formation. Chem. Commun. 2014, 50, 16751677.

(16) Brunsveld, L.; Folmer, B. J. B.; Meijer, E. W.; Sijbesma, R. P. Supramolecular polymers. Chem. Rev. 2001, 101, 4071-4098.

(17) Ciferri, A. Supramolecular Gels, 2nd ed.; CRC Press: Boca Raton, FL, 2005.

(18) Weiss, R. G.; Terech, P. Molecular Gels: Materials with SelfAssembled Fibrillar Networks. Springer: Dordrecht, The Netherlands, 2005.

(19) Wang, R.; Geven, M.; Dijkstra, P. J.; Martens, P.; Karperien, M. Hydrogels by supramolecular crosslinking of terpyridine end group functionalized 8-arm poly(ethylene glycol). Soft Matter 2014, 10, $7328-7336$.

(20) Tam, A. Y.-Y.; Wong, K. M.-C.; Wang, G.; Yam, V. W.-W. Luminescent metallogels of platinum(II) terpyridyl complexes. Interplay of metal $\cdots$ metal, $\pi-\pi$ and hydrophobic-hydrophobic interactions on gel formation. Chem. Commun. 2007, 2028-2030.

(21) Song, S.; Song, A.; Feng, L.; Wei, G.; Dong, S.; Hao, J. Fluorescent hydrogels with tunable nanostructure and viscoelasticity for formaldehyde removal. ACS Appl. Mater. Interfaces 2014, 6, 18319-18328.

(22) Bhowmik, S.; Ghosh, B. N.; Rissanen, K. Transition metal ion induced hydrogelation by amino-terpyridine ligands. Org. Biomol. Chem. 2014, 12, 8836-8839.

(23) Chen, X.; Huang, Z.; Chen, S.-Y.; Li, K.; Yu, X.-Q.; Pu, L. Enantioselective gel collapsing: a new means of visual chiral sensing. $J$. Am. Chem. Soc. 2010, 132, 7297-7299.

(24) Kishimura, A.; Yamashita, T.; Aida, T. Phosphorescent organogels via "Metallophilic" interactions for reversible RGB-color switching. J. Am. Chem. Soc. 2005, 127, 179-183.

(25) Rana, U.; Chakraborty, C.; Pandey, R. K.; Hossain, M. D.; Nagano, R.; Morita, H.; Hattori, S.; Minowa, T.; Higuchi, M. Selective DNA recognition and cytotoxicity of water-soluble helical metallosupramolecular polymers. Bioconjugate Chem. 2016, 27, 2307-2314.

(26) Tu, T.; Assenmacher, W.; Peterlik, H.; Weisbarth, R.; Nieger, M.; Dötz, K. H. An air-stable organometallic low-molecular-mass gelator: synthesis, aggregation, and catalytic application of a palladium pincer complex. Angew. Chem., Int. Ed. 2007, 46, 6368-6371.

(27) Eryazici, I.; Moorefield, C. N.; Newkome, G. R. Square-planar $\mathrm{Pd}(\mathrm{II}), \mathrm{Pt}(\mathrm{II})$, and $\mathrm{Au}(\mathrm{III})$ terpyridine complexes: their syntheses, physical properties, supramolecular constructs, and biomedical activities. Chem. Rev. 2008, 108, 1834-1895.

(28) McMillin, D. R; Moore, J. J. Luminescence that lasts from $\mathrm{Pt}($ trpy $) \mathrm{Cl}^{+}$derivatives (trpy $=2,2^{\prime} ; 6^{\prime}, 2^{\prime \prime}$-terpyridine). Coord. Chem. Rev. 2002, 229, 113-121.

(29) Morgan, J. R.; Nguyen, D. V. X.; Frohman, A. R.; Rybka, S. R.; Zebala, J. A. Reversible metal-dependent destabilization and stabilization of a stem-chelate-loop probe binding to an unmodified DNA target. Bioconjugate Chem. 2012, 23, 2020-2024.

(30) Anthonysamy, A.; Balasubramanian, S.; Shanmugaiahb, V.; Mathivananb, N. Synthesis, characterization and electrochemistry of $4^{\prime}$-functionalized $2,2^{\prime}: 6^{\prime}, 2^{\prime \prime}$-terpyridine ruthenium(II) complexes and their biological activity. Dalton Trans. 2008, 2136-2143.

(31) Amat, A. M.; Arques, A.; Galindo, F.; Miranda, M. A.; SantosJuanes, L.; Vercher, R. F.; Vicente, R. Acridine yellow as solar photocatalyst for enhancing biodegradability and eliminating ferulic acid as model pollutant. Appl. Catal., B 2007, 73, 220-226.

(32) Pérez-Ruíz, T.; Martínez-Lozano, C. V.; Tomás, V.; Fenoll, J. Spectrofluorimetric determination of formaldehyde by a flow-injection method based on its catalytic effect on the acridine yellow-bromate reaction. Anal. Bioanal. Chem. 2003, 375, 661-665.
(33) Chakraborty, B.; Basu, S. Deciphering the host-guest chemistry of Acridine Yellow and Cucurbit[7]uril: An integrated spectroscopic and calorimetric study. Chem. Phys. Lett. 2011, 507, 74-79.

(34) Grucela-Zajac, M.; Filapek, M.; Skorka, L.; Gasiorowski, J.; Glowacki, E. D.; Neugebauer, H.; Schab-Balcerzak, E. Thermal, optical, electrochemical, and electrochromic characteristics of novel polyimides bearing the Acridine Yellow moiety. Mater. Chem. Phys. 2012, 137, 221-234.

(35) Perera, V. P. S.; Pitigala, P. K. D. D. P.; Senevirathne, M. K. I.; Tennakone, K. A solar cell sensitized with three different dyes. Sol. Energy Mater. Sol. Cells 2005, 85, 91-98.

(36) Liu, S. P.; Chen, S.; Liu, Z. F.; Hu, X. L.; Li, T. S. Resonance Rayleigh scattering spectra of interaction of sodium carboxymethylcellulose with cationic acridine dyes and their analytical applications. Anal. Chim. Acta 2005, 535, 169-175.

(37) Brummelkamp, T. R.; Bernards, R.; Agami, R. A system for stable expression of short interfering RNAs in mammalian cells. Science 2002, 296, 550-553.

(38) Baskića, D.; Popovića, S.; Ristićb, P.; Arsenijevića, N. N. Analysis of cycloheximide-induced apoptosis in human leukocytes: Fluorescence microscopy using annexin $\mathrm{V} /$ propidium iodide versus acridin orange/ethidium bromide. Cell Biol. Int. 2006, 30, 924-932.

(39) Harris, T. A.; Yamakuchi, M.; Ferlito, M.; Mendell, J. T.; Lowenstein, C. J. MicroRNA-126 regulates endothelial expression of vascular cell adhesion molecule 1. Proc. Natl. Acad. Sci. U.S.A. 2008, 105, 1516-1521.

(40) Krützfeldt, J.; Rajewsky, N.; Braich, R.; Rajeev, K. G.; Tuschl, T.; Manoharan, M.; Stoffel, M. Silencing of microRNAs in vivo with antagomirs. Nature 2005, 438, 685-689.

(41) Oommen, S.; Anto, R. J.; Srinivas, G.; Karunagaran, D. Allicin (from garlic) induces caspase-mediated apoptosis in cancer cells. Eur. J. Pharmacol. 2004, 485, 97-103.

(42) Saeidnia, S.; Abdollahi, M. Are other fluorescent tags used instead of ethidium bromide safer? Daru, J. Pharm. Sci. 2013, 21, 71.

(43) Renvoizé, C.; Biola, A.; Pallardy, M.; Bréard, J. Apoptosis: Identification of dying cells. Cell Biol. Toxicol. 1998, 14, 111-120.

(44) Sunahara, H.; Urano, Y.; Kojima, H.; Nagano, T. Design and synthesis of a library of BODIPY-based environmental polarity sensors utilizing photoinduced electron-transfer-controlled fluorescence ON/ OFF switching. J. Am. Chem. Soc. 2007, 129, 5597-5604.

(45) Hu, R.; Lager, E.; Aguilar-Aguilar, A.; Liu, J.; Lam, J. W. Y.; Sung, H. H. Y.; Williams, I. D.; Zhong, Y.; Wong, K. S.; Peña-Cabrera, E.; Tang, B. Z. Twisted intramolecular charge transfer and aggregationinduced emission of BODIPY derivatives. J. Phys. Chem. C 2009, 113, $15845-15853$.

(46) Mukherjee, S.; Thilagar, P. Fine-tuning dual emission and aggregation-induced emission switching in NPI-BODIPY dyads. Chem.-Eur. J. 2014, 20, 9052-9062.

(47) Hu, R.; Gómez-Durán, C. F. A.; Lam, J. W. Y.; BelmonteVázquez, J. L.; Deng, C.; Chen, S.; Ye, R.; Peña-Cabrera, E.; Zhong, Y.; Wong, K. S.; Tang, B. Z. Synthesis, solvatochromism, aggregationinduced emission and cell imaging of tetraphenylethene-containing BODIPY derivatives with large Stokes shifts. Chem. Commun. 2012, 48, 10099-10101.

(48) Choi, S.; Bouffard, J.; Kim, Y. Aggregation-induced emission enhancement of a meso-trifluoromethyl BODIPY via J-aggregation. Chem. Sci. 2014, 5, 751-755.

(49) Loudet, A.; Burgess, K. BODIPY dyes and their derivatives: syntheses and spectroscopic properties. Chem. Rev. 2007, 107, 48914932.

(50) Kowada, T.; Maeda, H.; Kikuchi, K. BODIPY-based probes for the fluorescence imaging of biomolecules in living cells. Chem. Soc. Rev. 2015, 44, 4953-4972.

(51) Lee, J.-S.; Kang, N.-y.; Kim, Y. K.; Samanta, A.; Feng, S.; Kim, H. K.; Vendrell, M.; Park, J. H.; Chang, Y. T. Synthesis of a BODIPY library and its application to the development of live cell Glucagon imaging probe. J. Am. Chem. Soc. 2009, 131, 10077-10082.

(52) Yang, L.; Ji, Y.-J.; Yin, J.-F.; Wu, Y.; Fan, H.; Zhang, Y.; Kuang, G.-C. Amphiphilic BODIPY derivatives: the solvophobic effect on 
their photophysical properties and bioimaging in living cells. Soft Matter 2016, 12, 8581-8587.

(53) Basumatary, B.; Reddy, R. V. R.; Bhandary, S.; Sankar, J. Gallium(III)corrole-BODIPY hybrid: novel photophysical properties and first observation of B-F..F interactions. Dalton Trans. 2015, 44, 20817-20821.

(54) Nano, A.; Retailleau, P.; Hagon, J. P.; Harriman, A.; Ziessel, R. A hybrid bis(amino-styryl) substituted Bodipy dye and its conjugate diacid: synthesis, structure, spectroscopy and quantum chemical calculations. Phys. Chem. Chem. Phys. 2014, 16, 10187-10198.

(55) Rousseau, T.; Cravino, A.; Ripaud, E.; Leriche, P.; Rihn, S.; De Nicola, A.; Ziessel, R.; Roncali, J. A tailored hybrid BODIPYoligothiophene donor for molecular bulk heterojunction solar cells with improved performances. Chem. Commun. 2010, 46, 5082-5084.

(56) Babu, S. S.; Praveen, V. K.; Ajayaghosh, A. Functional $\pi$-gelators and their applications. Chem. Rev. 2014, 114, 1973-2129.

(57) García, O.; Garrido, L.; Sastre, R.; Costela, A.; García-Moreno, I. Synthetic strategies for hybrid materials to improve properties for optoelectronic applications. Adv. Funct. Mater. 2008, 18, 2017-2025.

(58) García, O.; Sastre, R.; del Agua, D.; Costela, A.; García-Moreno, I. New Fluorinated polymers doped with BODIPY chromophore as highly efficient and photostable optical materials. Chem. Mater. 2006, $18,601-602$.

(59) Lee, C. Y.; Farha, O. K.; Hong, B. J.; Sarjeant, A. A.; Nguyen, S. T.; Hupp, J. T. Light-harvesting metal-organic frameworks (MOFs): efficient strut-to-strut energy transfer in Bodipy and Porphyrin-based MOFs. J. Am. Chem. Soc. 2011, 133, 15858-15861.

(60) Wada, A.; Tamaru, S.-i.; Ikeda, M.; Hamachi, I. MCMenzyme-supramolecular hydrogel hybrid as a fluorescence sensing material for polyanions of biological significance. J. Am. Chem. Soc. 2009, 131, 5321-5330.

(61) Biswas, A.; Dubey, M.; Mukhopadhyay, S.; Kumar, A.; Pandey, D. S. Anion triggered metallogels: demetalation and crystal growth inside the gel matrix and improvement in viscoelastic properties using Au-NPs. Soft Matter 2016, 12, 2997-3003.

(62) Lee, Y. H.; Nghia, N. V.; Go, M. J.; Lee, J.; Lee, S. U.; Lee, M. H. Terpyridine-Triarylborane conjugates for the dual complexation of zinc(II) cation and fluoride anion. Organometallics 2014, 33, 753-762.

(63) Singh, R. S.; Yadav, M.; Gupta, R. K.; Pandey, R.; Pandey, D. S. Luminescent N,O-chelated chroman-BF2 complexes: structural variants of BODIPY. Dalton Trans. 2013, 42, 1696-1707.

(64) Smalley, S. J.; Waterland, M. R.; Telfer, S. G. Heteroleptic dipyrrin/bipyridine complexes of ruthenium(II). Inorg. Chem. 2009, $48,13-15$.

(65) Hanson, K.; Tamayo, A.; Diev, V. V.; Whited, M. T.; Djurovich, P. I.; Thompson, M. E. Efficient dipyrrin-centered phosphorescence at room temperature from bis-cyclometalated iridium(III) dipyrrinato complexes. Inorg. Chem. 2010, 49, 6077-6084.

(66) Tan, Y.; Gao, J.; Yu, J.; Wang, Z.; Cui, Y.; Yang, Y.; Qian, G. A new fluorescent probe for distinguishing $\mathrm{Zn}^{2+}$ and $\mathrm{Cd}^{2+}$ with high sensitivity and selectivity. Dalton Trans. 2013, 42, 11465-11470.

(67) Perrin, D. D.; Armango, W. L. F.; Perrin, D. R. Purification of Laboratory Chemicals; Pergamon: Oxford, U.K., 1986.

(68) Zhang, C.; Zhao, J.; Wu, S.; Wang, Z.; Wu, W.; Ma, J.; Guo, S.; Huang, L. Intramolecular RET enhanced visible light-absorbing bodipy organic triplet photosensitizers and application in photooxidation and triplet-triplet annihilation upconversion. J. Am. Chem. Soc. 2013, 135, 10566-10578. 